\title{
Arte e dança: estruturas ceno-visuais e a poética expositiva da arte
}

Sonia Salcedo del Castillo*

http://dx.doi.org/10.22409/poiesis.1829.269280

RESUMO: Este artigo aborda a relação entre arte e dança no curso da história da arte recente com o objetivo de identificar origens de estruturas ceno-visuais inerentes ao contexto artístico contemporâneo, sobretudo no que se refere à sua veiculação por meio das exposições de arte. A partir da ideia de temporalidade expandida, que questionou tanto a objetualidade na arte quanto o movimento na dança, tece analogias entre proposições vanguardistas do início do século XX e experimentalistas de meados do mesmo século, buscando ecos produtivos nos dias de hoje capazes de embasar um melhor entendimento da poética expositiva atual enquanto lugar de fricção treatral.

PALAVRAS-CHAVE: dança, arte, exposição

ABSTRACT: This article discusses the relationship between art and dance in the course of recent art history with the aim of identifying the origins of ceno-visual structures inherent in the contemporary artistic context, especially in terms of its use through art exhibitions. From the idea of expanded temporality, which questioned both objectualism in art and the movement in dance, it draws analogies between avant-garde propositions of the beginning of the 20th century and experimentalists of the mid-20th century, searching for productive echoes in the present day, capable of supporting a better understanding of the current expository poetics as a place of theatrical friction.

KEYWORDS: dance, art, exhibition

\footnotetext{
*Sonia Salcedo del Castillo é arquiteta e urbanista, artista pesquisadora, integrante da Comissão Curatorial do CEAV-Funarte, autora de publicações no campo expositivo, docente da EAV / Parque Lage, doutora em artes visuais pela EBA-UFRJ, é bolsista do Programa Pós-Doutorado Junior pelo CNPq em Estudos da Cena (PPGAC-UFRJ). E-mail: salcedocastillo@gmail.com.
} 
É preciso adorar dançar para persistir. A dança não dá nada em retorno, nem manuscritos a guardar, nem pinturas a colocar na parede ou mesmo a expor nos museus, nem poemas a publicar ou vender; nada salva esse instante fugaz, único, quando você se sente viver. -- Merce Cunningham

Se pararmos para uma rápida reflexão sobre a relação entre dança e artes visuais no curso da história, Degas, Rodin e Matisse parecem nomes impossíveis de serem esquecidos. Mas estimulando as ideias, lembramos também de Yves Klein e, por analogia, intuímos sutilezas na action paiting de Jackson Pollock, dado seu fluir de gesto, aparentemente aleatório, mas de uma precisão formal quase aristotélica. Assim, feito um misto de corpo, atitude, deslocamento... Não de forma distinta, nos remetemos ainda ao aleatório da música de John Cage, à maneira de um existir no espaço da contingência...

Progressivamente, como se puxássemos o fio de um novelo, deparamo-nos com uma espécie de leitmotiv comum às propostas artísticas mais radicais, como as lançadas pelas vanguardas históricas do início do século XX e pela geração experimentalista deflagrada em meados dos anos 1950, qual seja: um questionamento sobre o objeto artístico e, consequentemente, um interesse sobre uma temporalidade, não mais sintética como aquela peculiar ao objeto escultórico, mas expandida. Portanto, há uma temporalidade pertinente ao movimento.

Ao explorarmos o diálogo entre arte e dança, notamos uma dissolução de fronteiras entre seus campos de conhecimento. A arte do corpo em movimento revela um processo sinestésico que se mescla ao hibridismo que caracteriza a arte contemporânea. E nesse desnovelar, que estabelece analogia entre a dança e as artes visuais, é possível observar estruturas (vejam, não esculturas) que poderíamos alcunhar de ceno-visuais.

Das performances dadá aos ecos vanguardistas históricos a partir dos anos 1960, um novo vocabulário de ações e formas viabilizava que artistas e dançarinos afirmassem a ideia de abstração do corpo no campo da arte.

Isadora Duncan pioneiras da, nos anos 1920, elaborou coreografia liberta dos cânones do balé clássico, inspirada pela imagem de dançarinas retratadas nos vasos gregos. Por outro viés, pesquisas bauhausianas transitavam entre a dança e as artes visuais para empreender formas, como foi a proposta do balé Triádico de Oskar Schlemmer. Em lugar da fluidez de 
movimentos concebida por Duncan, Schlemmer irá criar uma antidança. Melhor, um construtivismo dançante, no qual o figurino se apresenta não como sinônimo de liberdade, mas como espécie de crisálida. Não era o corpo o gerador de formas. As formas de Schlemmer eram tão dominantes que ao corpo cabia incorporá-las feito concha.

Nos anos 1950, várias coreografias direcionaram-se ao uso de técnicas diferentes, empregando métodos composicionais que teciam paralelos com inovações pertinentes aos campos das artes visuais, da música e do teatro. O diálogo entre arte e dança parecia encontrar na performance seu lugar, sobretudo a partir das experiências do Black Montain College junto a Cage, entre muitos outros nomes como Andy Warhol, Robert Rauschenberg ou Nam June Paik.

Merce Gunningham, flexibilizando o corpo no lugar da rigidez postural do balé, introduziu coreografias recíprocas aos métodos composicionais da música de Cage. O corpo realiza, então, frases performáticas, segundo espacialização aleatória que, formalmente, assemelhava-se à produção expressionista abstrata. Não por acaso, Cunninghun teve Robert Rauschenberg como responsável pelo cenário de suas montagens.

James Waring recorreu a princípios visuais da colagem, avizinhando-se de colaboradores como Jasper Johns na elaboração de suas coreografias. Anna Halprin, mediante abordagem analítica acerca da anatomia e cinesiologia, propôs improvisações ao ar livre, cujos movimentos ou atos cotidianos estabeleciam relação direta com os espaços natural e sociopolítico e atos cotidianos, em consonância ao desejo artístico de misturar arte e vida, bem como influenciando muito o limiar da arte minimalista.

Na Nova York dos anos 1960, do Judson Theater - passando pelos happenings de Allan Kaprow - ao movimento do Fluxus, fazia-se "do corpo em movimento a sismografia dos estados da alma contemporânea. As idas e voltas estéticas, formais e conceituais entre coreógrafos e artistas são então incessantes"1. São exemplos dessa dupla atuação (coreografia/artes plásticas) nomes como Robert Morris e Robert Rauschenberg. Assim, não tardaria para que experimentos transversais tornassem os campos das artes interdependentes, dado a miscigenação poética adotada pelos artistas daqueles dias.

Em verdade, por atos de captura dessa liminaridade poética, um campo ampliado se abre com e para as artes. Sim, artes no plural, enquanto dispersão calculada, como indica Humbert Damisch (1984, p. 22). Algo da ordem da negação, do intervalo, da pausa, do 
entre-movimento. Algo familiar à consciência do espaço e, portanto, implicando em uma noção de presença, em existência e deslocamento. Espaço que não mais seria arquitetura nem paisagem, mas fricção de teatralidade. Espaço entre as frestas das artes, que contribuiu para conquistas artísticas modernas e pós-modernas, à revelia de críticos como foi Michael Fried em relação ao minimalismo.

Me remeto, aqui, ao texto de Rosalind Krauss, em seu livro Os caminhos da escultura moderna (KRAUSS, 1998, p. 241-289), sugestivamente intitulado de "Balés mecânicos". Em especial ao seu início, quando é relatada a celebre apresentação de Robert Morris, organizada pelo Living Theater em 1961. Tratava-se de uma apresentação de sete minutos, na qual abria-se a cortina de um palco e, no centro, via-se uma coluna de 2,40m de altura e 0,60m de largura, indelével, por cerca de três minutos e meio. De repente, ela desaba. E passados outros três minutos e meio, as cortinas se fecham. Ninguém entrava ou saia daquele palco. Nada acontecia nele senão a presença cênica daquela coluna, à maneira de um ator, ela em cena se apresentava.

Observe-se: o que há de especial nessa passagem diz respeito ao minimalismo. Ou seja, se refere ao crescente interesse que as artes (então ditas plásticas) passaram a ter pela ideia de uma temporalidade estendida: uma fusão da experiência temporal da escultura com o tempo real. Claro que isso trouxe mudanças profundas às experimentações estéticas, gerando um adensamento do vocabulário artístico que, por reciprocidade, tornaria o seu lugar de veiculação ou a exposição em parte constituinte da obra, conjuntamente à presença de seu espectador ou sujeito. Não por acaso, é nesse momento que a figura do curador, como a conhecemos hoje, surge. Não sem motivo, a exposição se torna uma espécie de metacampo que agencia distintos planos, à maneira da dança.

A partir do segundo pós-guerra, as artes envolviam-se progressivamente em experimentações estéticas que exploravam o tempo dramático projetado pelo movimento real. Quando um trabalho não transformava o contexto expositivo em contexto dramático, com frequência ele internalizava um sentido de ser (raison d'etre) enquanto agente de movimento. Todo espectro de arte cinética, arte de luz, esculturas ambientais (instalações) e quadros vivos, além das artes performáticas (happenings) e acessórios cênicos, são exemplares. 
Em verdade, desde o início do século XX, artistas exploravam esse binômio temporal entre o dramático e o real. Dois exemplos são Acessório de Luz de Moholy Nagy, que servia como elemento cênico, mediante o movimento de um torno central banhando o palco de luz e sombra, assim como o cenário de Picabia para o balé Relâche, no qual um pano de luz quase levava a plateia à cegueira quando aceso no segundo ato. Tanto a proposta de Nagy quanto a de Picabia foram produzidas especialmente para o palco por ser este um lugar de desenrolar de acontecimentos temporais e dramáticos. Embora ambos tivessem a luz como elemento formal, um se comporta como ator mecânico (o torno que gira criando alternâncias de luz), enquanto o outro, feito adereço dramático (os 370 spots que se acendem segundo uma deixa da dança). Já os móbiles de Calder, mediante a utilização de uma tecnologia bem menos elaborada, conseguiram animação semelhante, como espécie de metáfora do corpo ao deslocar-se no espaço. ${ }^{2}$

Essa inserção do espaço real no seio das proposições artísticas afina-se com as aspirações de estetas e dândis do passado. As vanguardas históricas, assim como todo o experimentalismo que propôs sua releitura em meados do século XX, aspiraram unir arte e vida, inclusive porque toda obra de arte tende a projetar uma imagem particular do mundo ou de como é estar nesse mundo.

Assim, as propostas artísticas que se desenvolveram a partir dos anos 1960 se voltaram para tudo que Ihes era exterior e contaminaram essa exterioridade em uma tática de desconstrução e de reconstrução estética.

Dessa maneira, entendemos o interesse pelo tempo como eixo da criação artística. Os happenings de Oldenburg, por exemplo, irão operar sobre a temporalidade de maneiras diversas. Ao explorar funções cotidianas (arrumar a mesa para uma refeição, pendurar roupas no varal), alinhavam-se a uma tradição da dança desenvolvida simultaneamente. É o caso das proposições coreográficas de Merce Cunnigham, dado seu crescente interesse pela coisificação do movimento. A isso correspondia uma temporalidade operacional, ou seja: ao tempo de nossas ações no mundo - que, note-se, é distinto do tempo tido como sintético inerente à escultura. Posteriormente, a isso correspondeu uma economia radical dos movimentos coreográficos que passou a ser conhecida por "dança da linguagem comum" e "do desempenho de tarefas" (carregar tijolos, mover colchões...). Tratava-se de substituir o ilusionismo pelo tempo real, esvaziando qualquer psicologização do executor. 
Novamente, dança e arte visual se tocam. Muito forte torna-se a relação que se pode estabelecer entre esse tipo de dança e a obra minimalista. Note-se, na dança da linguagem comum, assim como no espaço minimalista, o indivíduo não é sequer ele mesmo, mas um agente. Assim, não foi por acaso que um interesse pela nova dança moldou certas atitudes plásticas como as de Robert Morris, em 1961, ao ter reservado uma apresentação não de um ator, mas de uma coluna. A coluna foi antropomorfizada enquanto ator, sendo objeto, ao mesmo tempo, inexpressivo. ${ }^{3}$

Nesse sentido, é imprescindível fazer referência ao entendimento de espaço. Enxergar aquela coluna de Morris como sendo a mesma em posições diferentes é, acima de tudo, manifestar a ciência de que nosso conhecimento do espaço transcende a ideia de ser ele unicamente como uma grade.

Na soleira dos anos 1970, trabalhos como o Corredor de Bruce Nauman vão nos indicar a noção de coordenadas axiomáticas, além de reiterar relações temporais inerentes ao nosso mover-se no espaço que transcendem ao real vivido, uma vez que localizam no próprio corpo do observador um sentido de centro de movimento que, perceptivamente, é subvertido. À medida que o observador percorre o corredor e se aproxima de sua imagem em um monitor situado ao final do percurso, menor ele se percebe de costas, graças à posição de uma câmera, diametralmente, instalada naquele percurso.

Em suma, para as artes visuais, o interesse pela temporalidade distendida e, consequentemente, pela nova dança era, antes, ele mesmo, uma indagação sobre o objeto. O que ele é, como o conhecemos e o que significa tal conhecimento. Ao buscarem desvendar essas questões (no caso, voltadas ao universo do escultórico) enveredaram por liminaridades poéticas em suas relações com o contexto do observador, como espécie de ferramenta investigativa capaz de destruir modelos clássicos de entendimento para, dessa forma, reconstruí-los. Não sem motivo, a arte e a dança misturaram-se à cena da visualidade pública ou da visualidade da cena pública, travando uma relação filosófica como que se refletissem sobre o ser e o estar no mundo, para além das esferas cênicas e visuais.

Dado o interesse crescente pela temporalidade do movimento, do ato, do deslocamento, portanto do corpo e do espaço não apenas real, tanto por parte dos artistas cênicos quanto dos visuais, na soleira do século $X X$, assistimos à dança entrando em museus e galerias. Justo ela, que aprendemos ser efêmera, encerrada em celas que guardam o tempo ou que dele se 
guardam. Como em uma via de mão dupla, observamos aquelas mesmas caixas tornando-se um lugar onde o sentido de tempo tende a desaparecer. Onde passado, presente ou futuro integram-se em um mesmo plano. Onde, nos dias atuais, eterno e efêmero tendem a se unir. Não mais subservientes às disciplinas ou às especificidades, vemos o dançarino como uma espécie de agente do improvável, assim como observamos o artista como vetor do instável.

Exemplos disso são, de um lado, a produção da bailarina lisboeta Vera Mantero e, de outro, do artista visual carioca Franklin Cassaro. Igualmente exemplares são as propostas de Tunga, sobretudo em parceria com a bailarina Lia Rodrigues, bem como obras de Michel Grosman4, Pina Bausch, Olarfur Eliasson", Ricardo Aleixo e, antes, Hélio Oiticica e Lygia Pape ${ }^{6}$, dentre muitos outros.

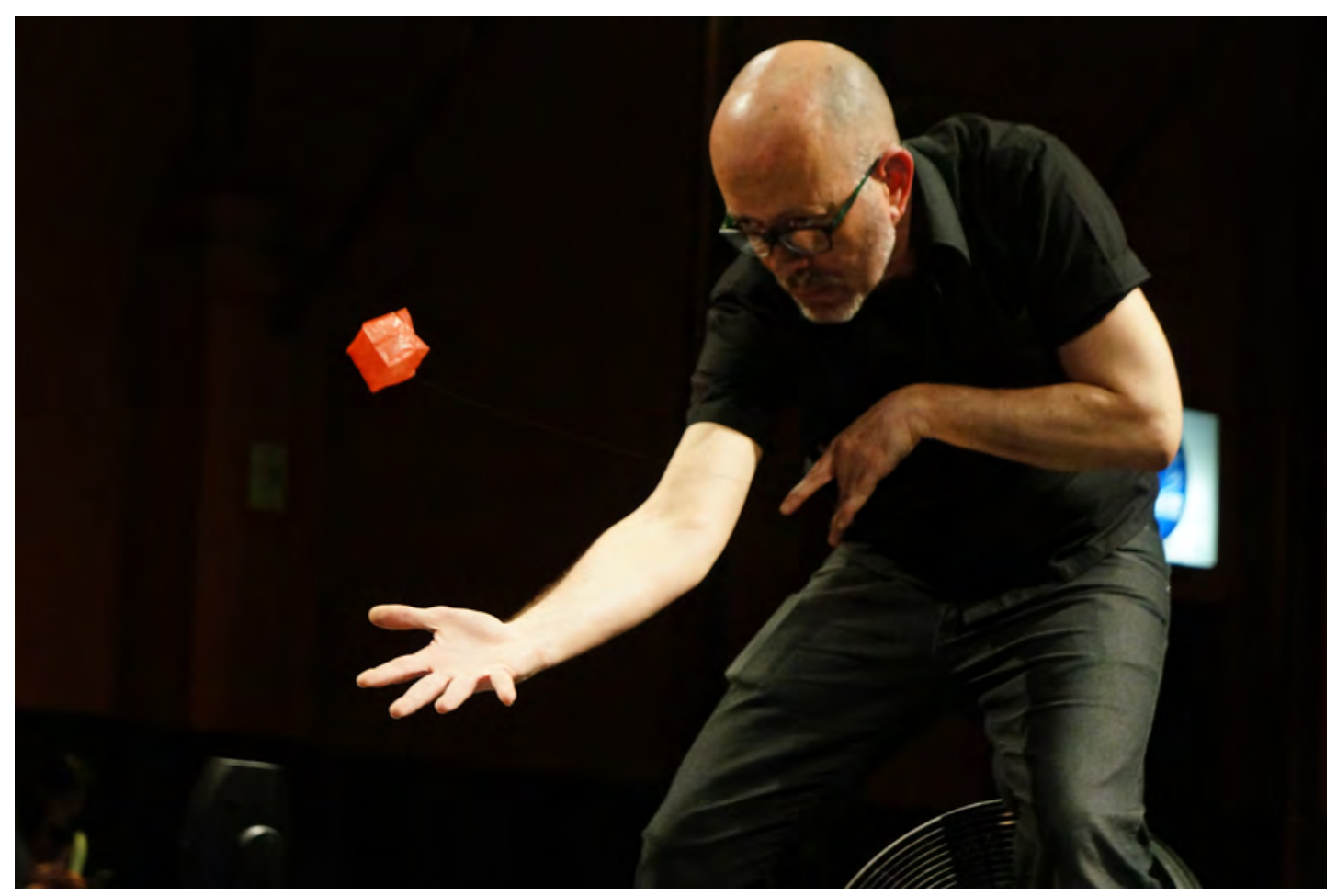

Franklin Cassaro, Atos escultóricos, 2016. (Foto: Clarisse Tarran) 




Lygia Pape, Balet Neoconcreto I, 1958.

(Fonte: https://tcmagazine.wordpress.com/tag/lygia-pape/)

Para concluir, tanto na qualidade de quem hoje pensa a dança de fora como na condição de quem já dançou certa vez, vislumbro familiaridade entre esse campo e aquele ao qual venho atuando artisticamente. Há muito em comum entre a atividade de um curador e daquele que mescla a autoria de uma coreografia/dramaturgia.

Principalmente no que se refere à convivialidade de alteridades, segundo escrita intervalar capaz de encontrar ligações por meio de analogias, colisões, atravessamentos visíveis/inteligíveis. Nessa escrita, no caso da curadoria (e de maneira semelhante a uma coreografia), existe um intento, algo a ser dito mediante léxico, uma escrita que se estende na arquitetura e se completa na experiência de seu fluxo (segundo o interesse despertado no espectador, grife-se: que se assemelha à ação dramática). A experiência entre sujeito e objeto reside no tempo, dado que o embate com a obra é duração, ato no espaço que implica visualidade, experiência e consciência. Vejam, isto se insere no âmbito da teatralidade. 
Em uma coreografia, assim como em uma curadoria, reside um conjunto de planos de composição (repetindo: ignição crítico-poética, analogias, colisões, atravessamentos, convivialidade entre). Planos que se entrecruzam, que se misturam, se atravessam, se interpõem uns aos outros. Isso ocorre, reciprocamente, por similaridade ou por oposição. Sem, no entanto, que esse transitar os impeça de se manterem interrelacionados nos campos que os agenciam: metacampo |dança x metacampo |exposição. Mas não só.

Tanto na dança quanto nas exposições, é possivel encontrar elos históricos sobre a hifenização arte-vida. E isso está relacionado ao agora, à ação. Sobretudo quando se reflete acerca das questões da contemporaneidade - aqui, bem entendido, como o momento em que a arte deixa de exigir do espectador uma atitude perceptiva, passando a demandar sua participação. Sua ação, o ato parado e seus intervalos indicam, assim, uma noção de presença que intercepta a órbita do teatral. Esse me parece ser o ponto de interseção entre aqueles dois metacampos anteriormente citados: dança e exposição.

Se, como afirma Rudolf Laban (ULLMAN, 1978, p. 139), a dança é para o movimento o que a poesia é para prosa, então, de fato, ela em muito dialoga com aquilo que indico ser expoesia ${ }^{7}$ (reflexão plástico-estética ou obra construída pela curadoria).

À maneira do poeta em relação à poesia, o artista elabora sua obra, assim como a curadoria realiza sua escritura expositiva e o coreógrafo sua notação coreográfica. Cada qual desenvolve sua linguagem para falar do mundo. Uma exposição, assim como a dança, não é objetual, pura e simplesmente. Ela é espaço poético que a atividade do curador, sua expoesis, torna lugar entre o real e o imaginário.

A dança me chega, assim, feito um tatear no escuro desejoso de encontrar algo... E vejam, ao que parece, aqui vislumbramos algo. As imagens de notações coreográficas confrontadas às expográficas, bem como às estruturas projetuais de Calder para um balé, falam por si sobre novas possibilidades de abordagem não apenas sobre a relação entre arte e dança, mas acima de tudo acerca da poética expositiva da arte como lugar entre cena e visualidade ou como preferimos sugerir: estrutura ceno-visual. 


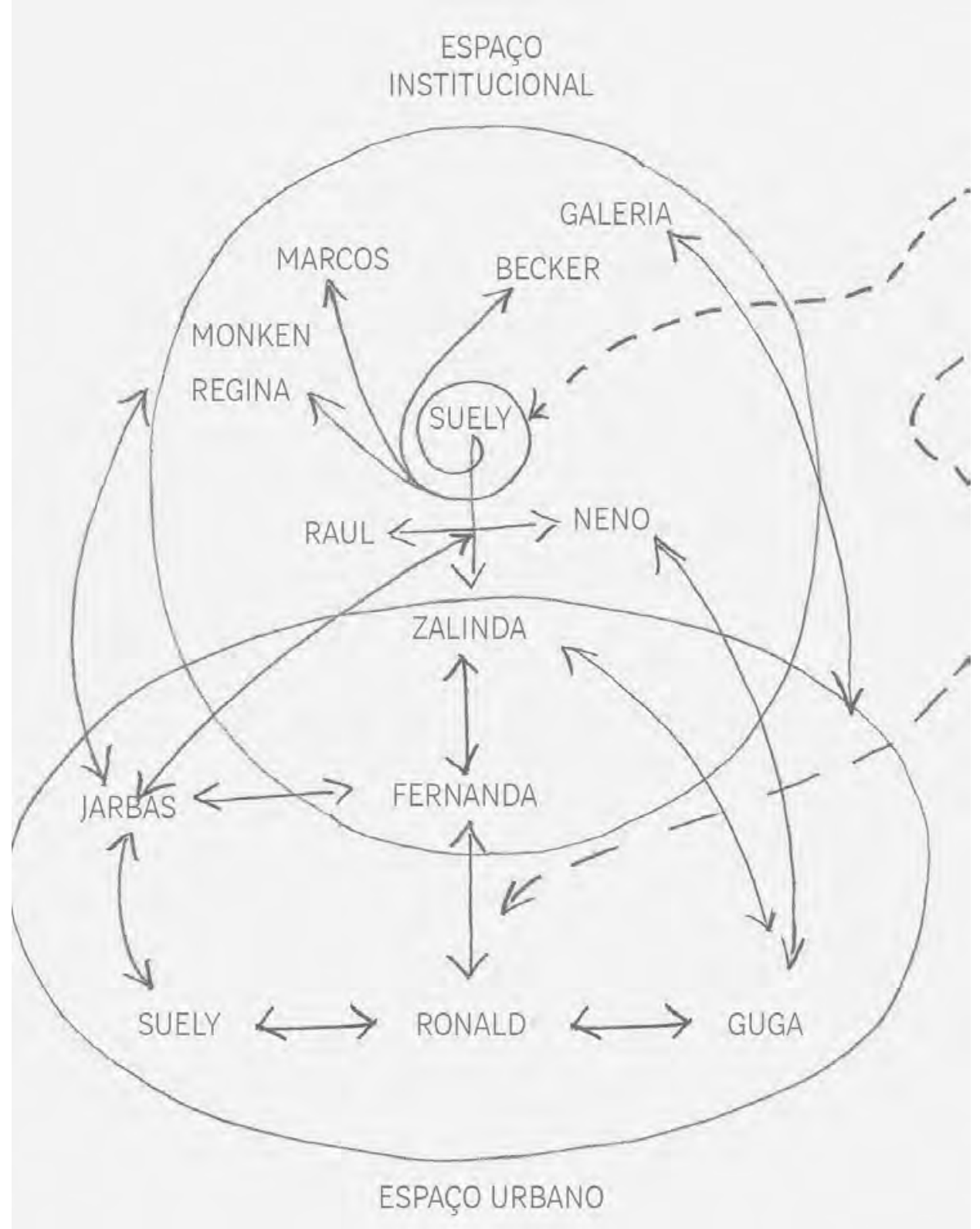

Notação expográfica, Sonia Salcedo. 


\section{WEIGHT}

Notação coreográfica, Rudolf Laban.
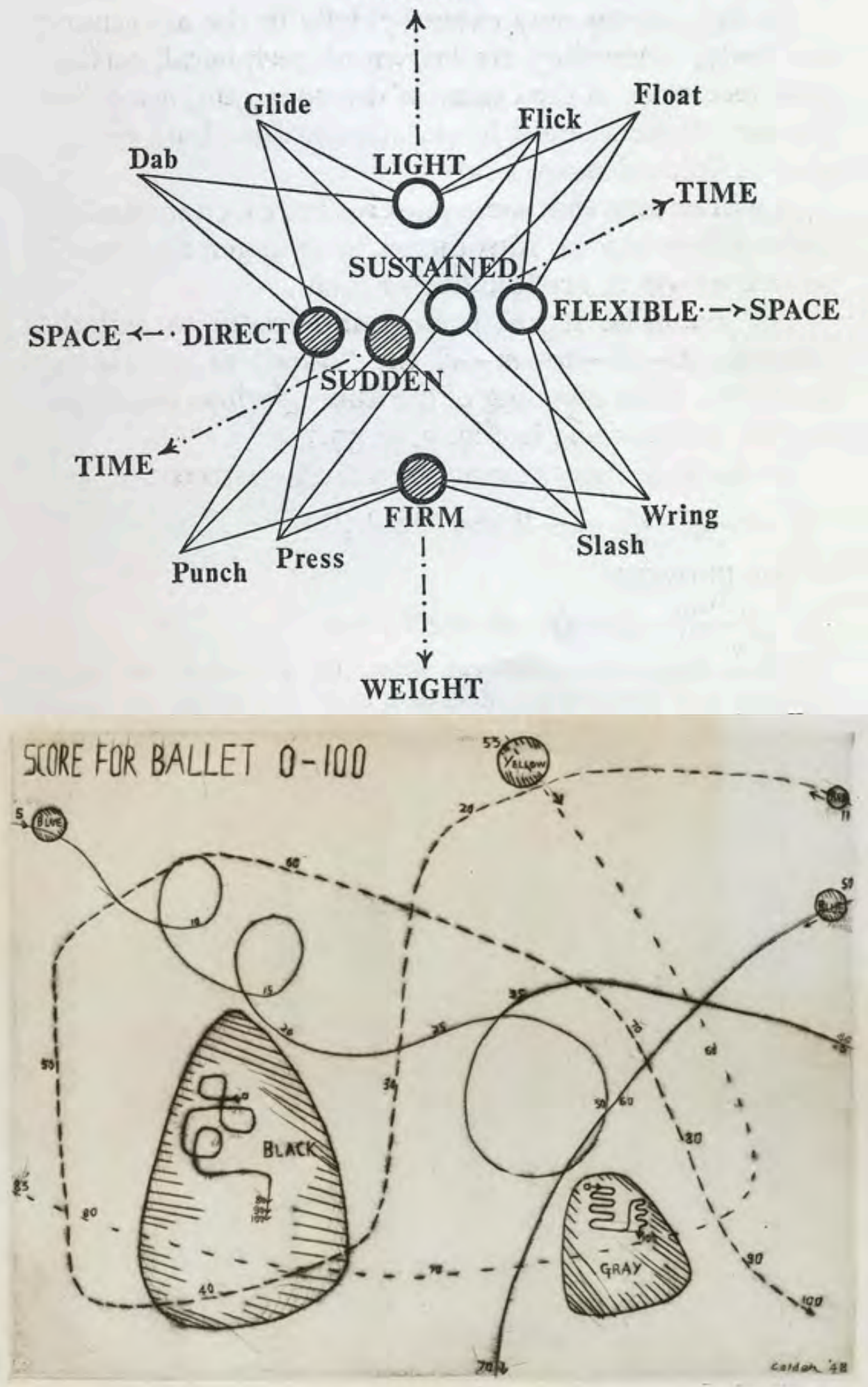

Score para um Balé, Calder, 1942.

(Fonte: https://www.mutualart.com/ Artwork/Score-for-Ballet/) 


\section{Notas}

1 Christine Macel e Emma Lavigne, curadoras da exposição Danser sa vie. Art et danse de 1900 à nos jours, no Centre Georges Pompidou de novembro de 2011 a abril de 2012

2 Inclusive, Martha Graham, percebendo a dramaticidade inata dos mobiles de Calder, se utilizou de uma série deles ampliados para apresentações de sua companhia de dança.

3 Lembro aqui da Local de Morris, 1963, quando o artista usou uma máscara moldada de seu próprio rosto por Johns como elemento capaz de ocultar a expressão de seu esforço ao transportar várias chapas de compensado.

4 https://youtu.be/egoPmkEJXNA

5 https://vimeo.com/32206496

6 O Balé Neoconcreto / consistia em sólidos geométricos (4 cilindros e 4 paralelepípedos) com 8 bailarinos dentro que se movimentavam no palco junto com jogos de luzes. Já o Balé Neoconcreto // era formado por um quadrado e um retângulo pintados de rosa e rosa e azul, respectivamente, com 2 bailarinos. Ambas as peças de Balé só foram apresentadas uma única vez (outras apresentações ocorreram depois como representação das originais).

7 Ver CASTILLO, 2014, p. 185-188

\section{Referências}

CASTILLO, Sonia Salcedo del. Arte de expor - curadoria como expoesis. Rio de Janeiro: NAU Editora, 2014.

CASTILLO, Sonia Salcedo del. Cenário da arquitetura da arte - montagens e espaços de exposições. Coleção Todas as artes. São Paulo: Martins Fontes, 2008.

DAMISCH, Humbert. Artes. In Enciclopédia Einaud. 3. Artes-Tonal. Lisboa: Impresa Nacional; Casa da Moeda, 1984.

GUIMARÃES, Adriano; GUIMARÃES, Fernando (orgs.). Nada Expandido. Brasília: Filhos do Beco, 2013.

KRAUSS, Rosalind. Caminhos da escultura moderna. São Paulo: Martins Fontes, 1998.

PHILLIPS, Lisa (ed.). The American Century: Art \& Culture, 1950-2000. Nova York: Whitney Museum of American Art, 1999. (catálogo de exposição)

ULLMAN, Lisa (org). Rudolf Laban-domínio do movimento. São Paulo: Summus, 1978.

\section{Vídeos}

https://youtu.be/egoPmkEJXNA

https://vimeo.com/32206496 